\title{
Studies on the distribution and abundance of plankton in Awba stream and reservoir, University of Ibadan
}

\author{
Emmanuel Teryila Tyokumbur*, Tonye Okorie \\ Department of Zoology, University of Ibadan, Ibadan, Nigeria; ${ }^{*}$ Corresponding Author: e.tyokumbur@mail.ui.edu.ng
}

Received 30 March 2013; revised 7 May 2013; accepted 20 June 2013

Copyright (C) 2013 Emmanuel Teryila Tyokumbur, Tonye Okorie. This is an open access article distributed under the Creative Commons Attribution License, which permits unrestricted use, distribution, and reproduction in any medium, provided the original work is properly cited.

\section{ABSTRACT}

Studies were carried out on the distribution and abundance of plankton in Awba stream and reservoir, University of Ibadan over a period of four months between November 2011 and February 2012. Studies were carried out at four selected stations comprising station 1 as the entry point of the stream into the University, which also served as the control, station 2 receiving sewage, station 3 downstream along the stream and at a point along Awba Reservoir serving as station $4.1 \mathrm{ml}$ aliquot of each plankton sample from the study stations were examined under a binocular microscope while identification of the plankton was carried out using standard textbooks. The results of the phytoplankton indicated the absence of Microcystis flos-aquae, Agmenellum and Oscillatoria limnetica in station 1 while members of the family bacillariophyceae appeared at all stations. All species of chlorophyceae family except Spirogyra were peculiarly absent at station 2. Other phytoplankton representatives at this point (station 2) included Microcystis, Anabaena, Oscillatoria and Melosira. Paramecium was the only zooplankton group that was absent in station 1 but the only species presented in station 2 . This station also revealed the lowest diversity indices and very low or no Jaccards coefficient of similarity with the other stations. The overall differences observed in the abundance, species richness, Margalef and Shannon-Wiener indices of diversity of plankton in the study reveal self purification or recovery downstream from the effluent discharge.

Keywords: Abundance; Distribution; Plankton;
Awba Stream; Reservoir

\section{INTRODUCTION}

The human inputs of complex mixture of domestic effluents from halls of residences and other sources in the University of Ibadan could lead to ecosystem perturbation consequences in Awba stream and Reservoir. The effects of these effluents on the water quality, aquatic life and the maintenance of a hitherto viable safety of humans environmentally or occupationally exposed to the perturbation are of primary ecological concern.

The use of diverse methods for water quality monitoring is of importance to the management of fisheries, pollution, water supply, sewage treatment reservoirs and freshwater impoundments [1]. This involves the assessment of water quality which is a function indicative of the pollution status of the water body. Changes and variations in the water quality are reflected in the biotic community structure in which the most vulnerable die while the most sensitive species survive to act as indicators of pollution. Based on this criteria, plankton (phytoplankton and zooplankton) are expected to reflect changes in the physico-chemical parameters as a result of effluent impact. By using biological variables to monitor the effects of effluent impacts, this incorporates the short and long-term adverse effects on living resources and ecological systems. The high degree of variability in natural ecosystems as well as in modified ones and the complexity of diverse organism reactions to stress from effluents limit the use and adoption of a uniform approach in biological assessment [2].

The main objectives of this study include to investigate changes in community structure of plankton of Awba stream and Reservoir, to compare results of the entry point of Awba stream into the University of Ibadan, assumed to be relatively unaffected by anthropogenic 
input of effluents with other selected stations, to study a short-term cycle in abundance, species composition and relative abundance with a view to providing background information on the distribution and abundance of plankton in Awba stream and Reservoir.

\section{MATERIALS AND METHODS}

\subsection{Review of the Study Area}

The study area covered 4 sampling stations in Awba stream and Reservoir within the University of Ibadan, Nigeria. The Awba stream flows into the University at the South-east end, and runs its course in a South-western direction, but still confined to the southern half of the University. At its south western end, the stream was dammed in 1962 at a point where it flowed through a natural valley. The Awba Reservoir popularly known as Awba Dam, lies between the latitudes $7^{\circ} 26^{\prime}-7^{\circ} 27^{\prime} \mathrm{N}$ and longitudes $3^{\circ} 53^{\prime}-3^{\circ} 54^{\prime} \mathrm{E}$. It is about 5.5 metres high, 140 metres long with a crest of 12.2 metres. With a maximum depth of 5.5 metres, the Reservoir can hold about 230 million litres of water when full. The stream throughout its course in the University has a length of 975 metres. $\mathrm{Up}$ to the zoological garden end; the water level is scarcely above $25 \mathrm{~cm}$ deep [3-5]. The water level in the Reservoir is regulated at a spill-way through which excess water flows out so the level remains almost constant throughout the rainy season. However, during the dry season, the water level recedes.

The 4 sampling stations include: Entry point of Awba stream into the University as station 1. A point after sewage discharge into the stream at the Nnamdi Azikiwe Hall Culvert as station 2. The entry point of Awba stream into the Reservoir behind the Faculty of Science building as station 3. A point at the shore of Awba Reservoir as station 4. The entry point of Awba stream into the University is taken as the control or a relatively unpolluted station upon which any change in the water quality, and abundance of plankton at stations 2, 3 and 4 can be assessed and compared. In between stations 1 and 2 precisely at the culvert on the road leading to Independence Hall from El-Kanemi Road, domestic wastewater from the Halls and Black market is discharged into the stream. The sewage from parts of the University community enters the stream mainly at station 2 . The land on either side of the stream from station 1 to 2 is cultivated for agricultural purposes by staff within the University community. The Fishpond of the Department of Fisheries and Wildlife between station 1 and 2 contributes agricultural wastes from fertilization into Awba stream whenever the aquaria is emptied and when it overflows. Station 4 is taken as a point of reference for comparison with the other stations to assess the degree of self-purification of Awba stream from the effluent discharges down to the
Reservoir.

\subsection{Plankton Sampling}

Plankton samples were collected from the 4 stations using plankton net of mesh size $34 \mu \mathrm{m}$. The string was sometimes attached to the plankton net and held in a canoe and net waded in water for about 15 minutes on each sampling occasion at station 4. At other stations, plankton samples were obtained by pouring at least 15 bucketful water samples through the plankton net held by an Assistant. The Plankton filtered was poured into $250 \mathrm{ml}$ specimen bottles and formalin added for preservation.

Identification and estimation of plankton

In the laboratory $1 \mathrm{ml}$ aliquot of each plankton sample was examined under binocular microscope. Identification of the plankton was carried out using standard textbooks such as [6-9] and following the criteria of Greene [10]. The plankton was identified up to species level, others as far as practicable. The frequencies of occurrence, number and relative abundance of each plankton sample in monthly samples were estimated.

\subsection{Data Processing of Sample Results}

This involved the calculation of diversity indices such as Margalef's [11] and Shannon-Wiener [12] information function.

Margalef's d value is a measure of species richness which is expressed by the equation,

$$
\begin{aligned}
& d=\underline{S}-1 \\
& \log _{\mathrm{e}} \mathrm{N}
\end{aligned}
$$

where,

$\mathrm{d}$ = Margalef's diversity index

$\mathrm{S}=$ Number of species

$\mathrm{N}=$ Number of individuals

Shannon-Wiener information function (Hs) is expressed

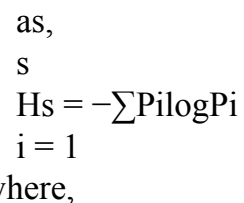

Hs = Shannon-Wiener diversity index

$\mathrm{S}=$ Total number of species

$\mathrm{Pi}=$ Observed proportion of individuals that belong to the ith species $(i=1,2,3 \ldots n)$

Measurement of similarity between samples employed Jaccard coefficient [13]. Jaccards coefficient (Jc) is expressed as,

$$
\begin{aligned}
& \mathrm{Jc}=\underline{\mathrm{c}} \times 100 \\
& \mathrm{a}+\mathrm{b}+\mathrm{c}
\end{aligned}
$$

where,

$a=$ Number of species in sample a only

$\mathrm{b}=$ Number of species in sample $\mathrm{b}$ only 
$\mathrm{c}=$ Number of species common to both samples.

\section{RESULTS AND DISCUSSION}

\subsection{Water Quality and Plankton Abundance}

The results in Table 1 indicate the absence of Microcystis flos-aquae, Agmenellum and Oscillatoria limnetica in station 1 . Members of the family bacillariophyceae appeared at all stations, while species of chlorophyceae family except Spirogyra were peculiarly absent from station 2. Peridinium (Family dinophyceae) and Phacus (Family euglenophyceae) were also absent from station 2. Spirogyra was the most abundant phytoplankton in station 1 (17) while the least were Anabaena, Oscillatoria formosa, Anabaenopsis and Melosira (1). In station 2, Nostoc was the most abundant (22), while the least were Synedra and Spirogyra (1). In station 3, Closterium was the most frequently encountered (19), while the least abundant was Oscillatoria limnetica (4). The most abundant phytoplankton in station 4 was Closterium (25) while the least was Microcystis aeruginosa (3).

The results of the zooplankton abundance and distri- bution in the study are shown in Table 2.

The result of the abundance of zooplankton shows that Paramecium (Protozoa) was absent at station 1 but was the only group presented in station 2 , while the representative species of rotifera, cladocera and copepoda were never encountered at station 2, but occurred at all the other stations with varying abundance. The most abundant groups in station 1 were Tricocerca (all rotifera) and Keratella (co-dominant, 5), while the least was Diaphanosoma (cladocera), (1). Paramecium (Protozoa) was the only group presented in station 2 (20). In station 3, Tricocerca was the most abundant (11), while Filina (rotifera) and Moina (cladocera) were the least abundant (3). In station 4, Asplanchna (rotifera) was the most abundant (25) while the least abundant was Paramecium (Protozoa), (9).

Table 3 shows the Margalef's diversity indices and Shannon-Wiener Information function (Hs) for the study.

The Margalef's diversity indices fell in the ranges 0.207 (December, 2011, station 2) to 3.882 (station 1, November 2011). Higher diversity indices were recorded at stations 1,3 and 4 , while the lowest was at station 2

Table 1. The abundance and distribution of phytoplankton in the study.

\begin{tabular}{|c|c|c|c|c|c|c|c|c|c|}
\hline Family & STATION 1 & $\%$ & STATION 2 & $\%$ & STATION 3 & $\%$ & STATION 4 & $\%$ & TOTAL \\
\hline \multicolumn{10}{|l|}{ CYANOPHYCEAE } \\
\hline \multicolumn{10}{|l|}{ Microcystis } \\
\hline aeruginosa & 11 & 30 & 19 & 57.6 & 10 & 30.3 & 3 & 9.1 & 43 \\
\hline M. flos-aquae & - & - & 14 & 48.3 & 9 & 31.0 & 6 & 20.7 & 29 \\
\hline Agmenellum & - & - & 16 & 47.1 & 11 & 32.4 & 7 & 20.5 & 34 \\
\hline Anabaena & 1 & 3.1 & 16 & 50.0 & 5 & 15.6 & 10 & 31.3 & 32 \\
\hline Osillatoria formosa & 1 & 3.7 & 11 & 40.7 & 8 & 29.6 & 7 & 25.9 & 27 \\
\hline O. limnetica & - & - & 12 & 60.0 & 4 & 20.0 & 4 & 20.0 & 20 \\
\hline Pseudonabaena & 3 & 8.3 & 18 & 50.0 & 9 & 25.0 & 6 & 16.7 & 36 \\
\hline Anabaenopsis & 1 & 3.2 & 16 & 51.8 & 9 & 20.9 & 5 & 16.1 & 31 \\
\hline Nostoc & 1 & 2.2 & 22 & 48.9 & 13 & 28.9 & 9 & 20.0 & 45 \\
\hline \multicolumn{10}{|l|}{ BACILLARIOPHYCEAE } \\
\hline Synedra & 7 & 24.2 & 1 & 3.4 & 6 & 20.8 & 15 & 51.7 & 29 \\
\hline Navicula & 12 & 24.5 & 5 & 10.2 & 11 & 22.4 & 21 & 42.9 & 49 \\
\hline Melosira & 1 & 2.9 & 18 & 51.4 & 11 & 31.4 & 5 & 14.3 & 35 \\
\hline Coscinodiscus & 9 & 27.3 & 2 & 6.1 & 8 & 24.2 & 14 & 42.2 & 33 \\
\hline \multicolumn{10}{|l|}{ CHLOROPHYCEAE } \\
\hline Pediastrum simplex & 6 & 21.4 & - & - & 7 & 25.0 & 15 & 53.6 & 28 \\
\hline P. duplex & 10 & 30.3 & - & - & 6 & 18.2 & 17 & 51.5 & 33 \\
\hline Staurastrum & 7 & 26.9 & - & - & 7 & 26.9 & 12 & 46.2 & 26 \\
\hline Scenedesmus & 5 & 15.2 & - & - & 10 & 30.3 & 18 & 54.5 & 33 \\
\hline Closterium & 4 & 10.5 & - & - & 19 & 23.7 & 25 & 65.8 & 38 \\
\hline Spirogyra & 17 & 37.8 & 1 & 2.2 & 16 & 35.6 & 11 & 2.4 & 45 \\
\hline \multicolumn{10}{|l|}{ DINOPHYCEAE } \\
\hline Peridinium & 7 & 2.26 & - & - & 10 & 32.3 & 14 & 45.1 & 31 \\
\hline \multicolumn{10}{|l|}{ EUGLENOPHYCEAE } \\
\hline Phacus & 4 & 14.8 & - & - & 10 & 37.0 & 13 & 48.2 & 27 \\
\hline Euglena & 6 & 15.4 & 3 & 7.6 & 15 & 38.5 & 15 & 38.5 & 39 \\
\hline Total & & & & & & & & & 733 \\
\hline
\end{tabular}


Table 2. The Abundance and distribution of zooplankton in the study.

\begin{tabular}{|c|c|c|c|c|c|c|c|c|c|}
\hline & \multicolumn{2}{|c|}{ Station 1} & \multicolumn{2}{|c|}{ Station 2} & \multicolumn{2}{|c|}{ Station 3} & \multicolumn{2}{|c|}{ Station 4} & \multirow[t]{2}{*}{ Total } \\
\hline & Total & $\%$ & Total & $\%$ & Total & $\%$ & Total & $\%$ & \\
\hline \multicolumn{10}{|l|}{ Protozoa } \\
\hline Paramecium & - & - & 20 & 51.3 & 10 & 25.6 & 9 & 23.1 & 39 \\
\hline \multicolumn{10}{|l|}{ ROTIFERA } \\
\hline Brachionus & 5 & 18.5 & - & - & 6 & 22.2 & 16 & 59.3 & 27 \\
\hline Anuraeopsis & 5 & 17.9 & - & - & 6 & 21.4 & 17 & 60.7 & 28 \\
\hline Tricocerca & 6 & 22.2 & - & - & 11 & 40.7 & 10 & 37.1 & 27 \\
\hline Filina & 3 & 13.0 & - & - & 3 & 13.0 & 17 & 74.0 & 23 \\
\hline Asplanchna & 4 & 11.4 & - & - & 6 & 17.2 & 25 & 71.4 & 35 \\
\hline Keratella & 6 & 17.6 & - & - & 10 & 29.4 & 18 & 53.0 & 34 \\
\hline \multicolumn{10}{|l|}{ CLADOCERA } \\
\hline Moina & 5 & 20.8 & - & - & 3 & 12.5 & 16 & 66.7 & 24 \\
\hline Diaphanosoma & 1 & 4.5 & - & - & 6 & 27.3 & 15 & 68.2 & 22 \\
\hline \multicolumn{10}{|l|}{ COPEPODA } \\
\hline Macrocyclops & 4 & 15.4 & - & - & 7 & 26.9 & 15 & 57.7 & 26 \\
\hline Senecella & 2 & 7.4 & - & - & 7 & 25.9 & 18 & 66.7 & 27 \\
\hline
\end{tabular}

Table 3. Margalef's Diversity indices and the Shannon-wiener information function (HS) for the four month study.

\begin{tabular}{cccccc}
\hline DIVERSITY INDICES & STATIONS & NOVEMBER 2011 & DECEMBER 2011 & JANUARY 2012 & FEBRUARY 2012 \\
\hline MARGALEF'S & 1 & 3.882 & 3.031 & 2.404 & 2.817 \\
DIVERSITY INDICES (d) & 2 & 0.216 & 0.207 & 0.221 & 0.439 \\
& 3. & 2.012 & 2.012 & 2.171 & 2.831 \\
Shannon-Wiener & 4 & 3.821 & 3.266 & 2,962 & 0.859 \\
Information function & 1 & 1.036 & 0.895 & 0.752 & 0.126 \\
(Hs) & 2 & 0.097 & 0.072 & 0.078 & 0.698 \\
& 3 & 0.785 & 0.738 & 0.978 & 0.901 \\
\hline
\end{tabular}

throughout the study. The low diversity indices recorded in station 2 generally followed a trend of gradual increase downstream to station 4, the Shannon-Wiener Information Function (Hs) ranged between 0.072 (station 2, December 2011) and 1.036 (station 1, November, 2011). This also followed the variation trend of the Margalef's diversity indices.

Table 4 shows Jaccard's coefficients for the four stations during the 4 month study. The lowest Jaccard's coefficient, 0 was recorded between stations 1 and 2 throughout the study. A similar trend was recorded between stations 2 and 4 from December 2011 to February 2012. The highest coefficient of 92.301 was recorded between stations 1 and 4 in November 2011. In all, stations 1 and 4 recorded high coefficient throughout the study, followed by stations 3 and 4 .

\section{CONCLUSIONS}

Estimates of plankton abundance and species composition in the study exhibited a pattern that indicates the effects of the effluent discharge on the stream. The species richness in station 1 (29) dropped to 16 at station 2 as a result of the effluent discharged at this point. Thus tolerant groups such as cyanophyceae, euglenophyceae and protozoa that survive under higher organic conditions abound [14-16]. At stations 3 and 4, the species richness was at the maximum encountered number of 33 each, indicating a remarkable improvement in the water quality as a result of self-purification downstream. The absence of relatively dominant plankton group in stations 1,3 and 4 can be attributed to the abundance of niches in these ecosystems as a result of favorable physico-chemical quality of the water at these points [17-20]. Margalef's 
Table 4. Jaccard's coefficients showing similarities between the four stations.

\begin{tabular}{ccccc}
\hline STATIONS & NOVEMBER 2011 & DECEMBER 2011 & JANUARY 2012 & FEBRUARY 2012 \\
\hline 1.2 & - & - & - & - \\
1.3 & $35.70,92.30,12.50$ & $15.40,75.00,14.30$ & $20.00,42.90$ & $36.40,41.70,25.00$ \\
1.4 & 6 & - & - & - \\
2.3 & 50.00 & 20.00 & 50.00 & 23.10 \\
2.4 & & & \\
3.4 & & & & \\
\hline
\end{tabular}

diversity indices (values) and Shannon Wiener Information function (HS) recorded in the study also reflect the effect of the physico-chemical quality of the effluents on the phytoplankton and zooplankton. Thus diversities at station 1 throughout the 4 month study were always high while it felled low at station 2 due to the anoxic conditions supporting only the hardy and tolerant phytoplankton and zooplankton. The remarkable increase in the diversity indices from station 2 downwards can be attributed to the improvement in the physico-chemical quality of the stream from the point of effluent discharge.

The overall differences observed in the abundance, species richness and diversity indices at station 1 (the control) and from station 2, effluent discharge point down to station 4 , indicate a self purification or recovery. This pattern as shown in the results involved an improvement downstream in the combination of plankton diversity and physico-chemical qualities of Awba stream receiving the effluent that supports the biota. The regular flow of the stream from station 2 to 4 and the abundance of macrophytes at the sides of the stream assisted in self purification as well as by turbulence and photosynthesis (Hynes, 1970).

Comparism of the community structure of plankton between the four stations

Jaccards coefficient between stations 1 and 2 showed no similarity throughout this study because, unlike station 1, station 2 is anoxic hence only supports a few tolerant and hardy species that exhibit a high degree of habitat-specificity. Hence there were few species common to both stations 1 and 2 .

The slight similarity between stations 1 and 3 (Example November, 2011: 35.70\%) can be attributed to the partial recovery of the stream at this point hence the low Jaccards coefficient. The high coefficients recorded between stations 1 and 4 indicate that the alterations in the physico-chemical quality of water obtainable at station 2 , have attained a high level of recovery as reflected in the species similarity.

The absence of similarity between stations 2 and 3, in January 2012 can be attributed to the receding water level in station 3 at this time of the year (dry season), thus excluding the usually similar phytoplankton and zooplankton common to both stations. The same reason ac- counts for the Nil Jaccards coefficient between stations 2 and 4 from December 2011 to February 2012.

Furthermore, values of parameters of the various classes of beneficial uses of water have been given [21], the classification of surface water qualities [22]. However, more studies are needed in order to assess the limnological (hydrological) conditions of a body of water in relation to the organisms presented therein for ecosystem health that would be beneficial to man. This is most vital when assessing community structure, productivity and other characteristics of the aquatic ecosystem [23].

\section{ACKNOWLEDGEMENTS}

Laboratory space and equipments were provided by the Department of Zoology, University of Ibadan, Ibadan, Nigeria.

\section{REFERENCES}

[1] Valentyne, D.R. (1957) Principles of modern limnology. American Scientist, 45, 218-244.

[2] Sattirn, J. (1981) Manual of methods in aquatic environment research-Part 8. Ecological assessment of pollution effects. Guideline for the FAO (GFCM/UNEP) Joint coordinated Project on Pollution in Mediterranean FAO, Fish Tech. Paper (209), 70.

[3] Hassan, A.T. (1974) Studies on the ecology of behaviour and life history of Libellulinae dragon flies. PhD Thesis, University of Ibadan.

[4] Omotosho, J.S. (1981) Comparative studies of the reproductive biology of the 2 cichlids Tilapia zilli and Sarotherodon niloticus from a small lake in Ibadan, Nigeria. M.Sc Thesis, University of Ibadan.

[5] Ugwumba, A.A.A. (1990) Food and feeding ecology of Oreochromis niloticus, Sarotherodon melanotheron and Heterotis niloticus (Pisces: Osteichthyes) in Awba Reservoir, Ibadan. Ph.D thesis, University of Ibadan.

[6] Needham, J.G. and Needham, P.R. (1975) A guide to the study of freshwater biology. 5th Edition, Holden Day Publisher, San Francisco.

[7] Odum, E.P. (1971) Fundamentals of ecology. W.B. Saunders Ltd., Philadelphia, 303-305, 319, 413.

[8] Hynes, H.B.N. (1960) The Biology of polluted waters. Liverpool University Press, Liverpool, 202.

[9] Hynes, H.B.N. (1970) The Ecology of running waters. 
University of Toronto Press, Toronto, pp. 94-111, 121182.

[10] Greene, J. (1963) Zooplankton of the River Sokoto, the Rhizopoda Testaceae. Proceedings of the Zoological Society of London, 141, 497-514. doi:10.1111/j.1469-7998.1963.tb06097.x

[11] Parsons, T.R., Takahashi, M. and Hargrave, B. (1977) Biological oceanographic processes. 2nd Edition, Pergamon Press, Oxford, 332 p.

[12] Shannon, C.E. and Weaver, W.W. (1963) The mathematical theory of communications. University of Illinois Press, Urbana, $117 \mathrm{p}$.

[13] Sokal, R.R. and Sneath, P.H.A. (1963) Principles of numerical taxonomy. Freeman, San Francisco.

[14] Oladimeji, A.A. and Wade, J.W. (1984) Effects of effluents from a sewage treatment plant on the aquatic organisms. Water, Air and Soil Pollution, 22, 1-7.

[15] Ekpu, E. (1989) Pollution in aquatic environment. M.Sc Seminar, University of Ibadan.

[16] Mason, C.F. (1990) Biological aspects of freshwater pollution. In: Harrison, R.M., Ed., Pollution: Causes effects and control. 2nd Edition, The Royal Society of Chemistry,
Cambridge, pp. 99-125.

[17] Gawfin, A.R. (1958) The effects of pollution on a midwestern stream. The Ohio Journal of Science, 58, 197208.

[18] Holden, J.M. and Green, J. (1960) The hydrology and plankton of the River Sokoto. Journal of Animal Ecology, 29, 65-84. doi: $10.2307 / 2271$

[19] Hawkes, H.A. (1962) River pollution II. Causes and effects. Butterworths, London, 311.

[20] Wilber, C.G. (1971) The biological aspects of water pollution. 2nd Edition, Charles Thomas Publisher, Springfield, $139 \mathrm{p}$.

[21] USAEC (1977) US Atomic Energy Commission Standards in environmental engineers handbook, Vol. 1, water pollution ed. by B.G. Liptak. Radnor, Pern. Chilton Book Company, New York.

[22] Ajayi, S.O. and Adelaye, S.A. (1977) Pollution studies on Nigerian rivers 1. Bulluliten of the Chemical Society of Nigeria, 2, 77.

[23] Adebisi, A.A. (1981) The physico-chemical hydrology, of tropical seasonal River-Upper Ogun River. Hydrobiologia, 79, 157-165. doi:10.1007/BF00006123 